\title{
NEURO-LINGUISTIC PROGRAMMING AS AN INNOVATION IN EDUCATION AND TEACHING
}

Paul Tosey and Jane Mathison, University of Surrey

\section{Summary}

Neuro-Linguistic Programming (NLP), an emergent, contested approach to communication and personal development created in the 1970's, has become increasingly familiar in education and teaching. There is little academic work on NLP to date. This article offers an informed introduction to, and appraisal of, the field for educators. We review the origins of NLP, and summarise its nature as a method of, and conceptual framework for, education and teaching, with brief examples of applications. We argue that NLP offers an innovative praxis, underpinned in principle by Bateson's epistemological thinking, which informs a distinctive methodology known as 'modelling'i ${ }^{\text {i }}$ The credibility of the field relies, in our view, on its ability to address seven critical issues. These form a possible research agenda and a focus for dialogue between NLP practitioner and academic communities.

\section{Key words}

Learning; epistemology; modelling; language. 


\section{INTRODUCTION}

Neuro-Linguistic Programming (NLP) has achieved considerable popularity as an approach to communication, learning and personal development. It appears to be used widely in education, yet is a subject about which the academic world is almost silent. It can therefore be difficult to gain an informed view of NLP amidst claims made by those with commercial interests in its promulgation.

Our intellectual project ${ }^{\mathrm{ii}}$ is concerned not with attempting to validate NLP, but with articulating and critically appraising its relevance to issues of learning, and promoting dialogue between practitioner and academic communities. We have extensive experience of using NLP in UK Higher Education for teaching and research (Tosey et al 2005), and we aim to acknowledge both the immense creativity to be found in NLP, and a range of critical concerns.

There is little precise data about the usage of NLP in education, training and teaching. NLP training providers exist around the globe, and we estimate that tens of thousands of participants have attended courses in the UK alone ${ }^{\mathrm{iii}}$. As evidenced by literature from NLP associations, websites, magazines and conferences, it is used by professional practitioners of many kinds, including educators. Its practical, goal-oriented approach has made it attractive in business (Knight 2002), where it is used for training, coaching and leadership development; it is also a recognised mode of psychotherapy in the $\mathrm{UK}^{\mathrm{iv}}$. In UK Higher Education, the University of Portsmouth launched a Masters programme in 2004 ${ }^{\mathrm{v}}$, and 
NLP has been taught within postgraduate modules at the University of Surrey since $1992^{\mathrm{vi}}$. NLP is also offered as professional development for educators, as in the UK Fast Track teaching programme provided by the CfBT Education Trust ${ }^{\mathrm{vii}}$.

There is little academic research into NLP. Besides our project, we know of recent activity in Germany ${ }^{\text {viii }}$, the USA ${ }^{\mathrm{ix}}$ and Belgium (Esser 2004), as well as elsewhere in the UK. Academic literature on NLP is sporadic and scattered across disciplines. In education and development this includes Brown (2003), Craft (2001), Stanton (1994), Thompson et al. (2002), and Tosey and Mathison (2003). Even this literature has little theoretically informed, critical discussion of NLP. The sole attempt at an NLP journal in a scholarly style, NLP World ${ }^{\mathrm{x}}$, appeared from 1994 until 2001, most of its articles being authored by NLP practitioners.

Here we identify seven critical issues that may have contributed to a lack of dialogue between practitioner and academic communities. These represent a synthesis of what we perceive to be important themes, informed by extensive acquaintance with literature and the field of practice. Those issues are:

1. NLP's pragmatic, anti-theoretical stance.

2. Its eclecticism and lack of theoretical coherence;

3. Weak linkage to contemporary academic work in relevant fields;

4. The belief that there is research evidence refuting NLP;

5. An unclear evidence base for NLP, and a lack of evaluation of its practices;

6. Ethical concerns about the way NLP is used in practice;

7. A lack of reflexive critique of NLP's discourse and social practices. 
Next we describe the origins and identity of NLP, including brief examples of applications in education.

\section{ORIGINS AND DEFINITION}

NLP was developed in the 1970's by Richard Bandler, then a student, and John Grinder, an associate professor of linguistics, at the University of California, Santa Cruz (Bostic St. Clair and Grinder 2001). The title 'NLP' reflects the principle that a person is a whole mind-body system, with consistent, patterned connections between neurological processes ('neuro'), language ('linguistic') and learned behavioural strategies ('programming') (Dilts et al 1980:2).

NLP emphasises the potential for self-determination (e.g. Bandler and Andreas 1985) through overcoming learnt self-limitation. Its motives were described, on the book jacket of Bandler and Grinder (1975a), as `sharing the resources of all those who are involved in finding ways to help people have better, fuller and richer lives'. Early publications have a psychotherapeutic emphasis because its initial studies were of Fritz Perls, the founder of Gestalt therapy, Virginia Satir, the family therapist, and Milton Erickson, the hypnotherapist. In common with forms of brief therapy (McDermott and Jago 2001), NLP challenges the assumption that personal change necessarily involves long-term therapy and is only possible with insight into the past (Bandler and Grinder 1979:6-7). It embodies a discourse of self-improvement and, like the emergent field of positive psychology (Linley et al 2006), emphasises well-being. NLP might also be said to reflect a postmodern 
relativism through its interest in individually defined and constructed `reality'; it draws explicitly on Vaihinger's (1924) principle that such constructions are tentative hypotheses according to which people act 'as-if' they were true.

Nevertheless, NLP has proved difficult to define succinctly. In promotional literature it has been described as `the art and science of human excellence in... communicating (etc.) ${ }^{\mathrm{xi}}$, which captures a technological emphasis. Dilts et al (1980) describe it as `the study of the structure of subjective experience', which foregrounds a methodological identity. Indeed originally NLP was described as a methodology (Bandler and Grinder 1975a:6), the purpose of which was to investigate exemplary communication, not to create a body of practice. Dilts and DeLozier (2000:849) add a third identity, arguing that NLP has epistemological, methodological and technological dimensions, which we now discuss.

\section{NLP AS EPISTEMOLOGY}

Whilst writers on NLP have generally declined to articulate it as theory - an issue to which we return below - we consider that it has a discernible theoretical thrust. Specifically, we regard Gregory Bateson's ideas (Bateson 1973) as a central influence on NLP. Bateson worked across disciplines, including anthropology and family therapy, and was a prominent member of the Macy conferences that developed the field of cybernetics. He wrote much about epistemological errors in theories of human interaction. Epistemology, according to Bateson, concerns; 'the problems of how we know anything, or more specifically, how we know what sort of world it is and what sort of creatures we are that can know...' (1973:284). 
Bateson lived in California in the 1970's (Bostic St.Clair and Grinder 2001:117-8, Lipset 1980:279) and took an interest in Bandler and Grinder, who by chance were his neighbours and, like him, were exploring communication and the mechanisms of perception. Bateson also enabled Bandler and Grinder to meet Milton Erickson (Bostic St.Clair and Grinder 2001: 175-8). The link between Bateson's work and NLP is also evidenced by Bateson's foreword to Bandler and Grinder's first publication (1975a:ixxi), a connection ignored in reviews of Bateson's work (Harries-Jones 1995; Lipset 1980).

Bateson is probably best known in education for his `levels of learning’ (Bateson 1973). His epistemological position implies a profound shift in understandings of learning and teaching, and appears related to contemporary theories of learning informed by complexity (Davis and Sumara 2006).

We, like others in the field, perceive a strong Batesonian influence on the principles of NLP, commonly articulated for practitioners as a set of presuppositions (e.g. Dilts 1998b), which in our view are essentially systemic. NLP is committed to a cybernetic view of how processes of perception and conceptualization are structured, and how they operate. This perspective would emphasise, among other things, the potential influence of the teacher's language patterns on the ways in which learners process information (Mathison 2004). We emphasise that from an NLP perspective, all teachers exercise this epistemological influence, regardless of whether they have trained in NLP; what NLP provides is a structured basis for understanding and utilising the nature of that influence. 


\section{NLP AS METHODOLOGY}

As noted above, NLP was developed originally as a methodology called `modelling’ (Dilts 1998a, Gordon and Dawes 2005), which is intended to make human capabilities available for others to learn; 'The objective of the NLP modeling process is not to end up with the one 'right' or 'true' description of a particular person's thinking process, but rather to make an instrumental map that allows us to apply the strategies that we have modelled in some useful way' (Dilts 1998a: 30).

Although the founders have gone their separate ways (McLendon 1989:117), Bandler and Grinder both still emphasise modelling as the core process that generates NLP applications through investigating the language patterns, behaviours, sequences of thought, and internal imagery of exponents of a chosen capability.

The nature of modelling is also contested. Dilts (1998a) emphasises a more conscious, analytical approach that employs conceptual frameworks, whilst Grinder (Bostic St Clair and Grinder 2001) argues that modelling is essentially an unconscious assimilation of the exemplar's capability. In practice these two modes are often used in combination.

Modelling has been used to identify cognitive strategies that lie behind capabilities such as motivating oneself, negotiating, spelling (Dilts et al 1980), and so on. Dilts (1994) has modelled a number of `strategies of genius’, including for example a creative process that appears to have been used by Walt Disney. 
As an example in Higher Education, the first author has modelled essay-writing, based on interviews with high-performing postgraduates. The result describes the beliefs and values of the exemplars, the process of conceiving and writing an essay, and the skills employed at each stage. It also highlights emotional and imaginative dimensions of the process, which seem underplayed in accounts of essay-writing in the literature. It has enabled other students to identify options for improvement; or to realise that their own values about grades are different from those of the exemplars, thus clarifying and affirming their choices about attainment.

This example also indicates the potential for NLP modelling to support `metalearning' (Jackson 2004). The methods used, while not unprecedented, may offer innovations in phenomenological research methods. For example, while phenomenography (Prosser and Trigwell 1999) shares a desire to illuminate learners' perceptual worlds, NLP enables a detailed appreciation of the structure of such experience through its especial emphasis on internal representations and imagery. Its framework of `submodalities’ (Bandler and MacDonald 1988) makes fine distinctions in the qualities of such representations.

\section{NLP AS TECHNOLOGY}

NLP offers a wide range of techniques and practical frameworks, described exhaustively in popular publications, including some aimed specifically at teachers and learners (Beaver 2002, Freeth 2003, O’Connor and Seymour 2000). These tools can be applied to virtually any aspect of learning and teaching; self-management, presentation skills, study 
skills, classroom management, teaching design, and so on. Here we give three brief examples:

First, the core language model of NLP, known as the `meta-model' (Bandler and Grinder 1975a), comprises a set of verbal patterns with corresponding forms of question that stimulate exploration of learners' constructs. From our experience, many teachers in Higher Education rely on broad distinctions between `open' and 'closed' questions. The meta-model offers an accessible and relatively sophisticated framework that enables the teacher to guide such enquiry more effectively.

Second, NLP pays particular attention to non-verbal communication, assuming that there are consistent - but individually unique - relationships between outer behaviour and internal processing. Teachers can enhance their observations to develop a finer appreciation of their learners' experiences and responses. NLP's position on non-verbal behaviour is derived from Bandler and Grinder's modelling of Milton Erickson, who could make such fine observational discriminations that these appeared to be intuitive not sensory.

Third, a range of techniques based on the principle of 'anchoring' (Bandler and Grinder 1979) utilise linkage between an experience and words, visual images, touch, and/or physical locations with which that experience is, or can be, associated. One application is for a teacher to re-access, physiologically as well as mentally, a selection of personal experiences that (for them) are strongly positive memories of themselves at their best, in other words. These can be linked together and associated (through a chosen 'anchor') with a context in which the teacher 
wants to have those 'resources' available (e.g. a challenging session). This can enhance confidence and capability in a chosen setting.

\section{CRITICAL CHALLENGES FOR NLP}

We now identify seven critical challenges, which seem to us to be significant for NLP.

\section{NLP's pragmatic, anti-theoretical stance}

NLP was created in order to be used. The founders took an explicitly anti-theoretical, pragmatic stance that mismatches the values of most academics: 'We have no idea about the "real" nature of things, and we're not particularly interested in what's "true". The function of modeling is to arrive at descriptions which are useful.' (Bandler and Grinder 1979:7).

This mismatch was probably compounded by the appearance of the term 'magic' in the titles of NLP's early publications. It is sometimes missed that Bandler and Grinder were not claiming to be magicians; their explicit project (1975a: 6) was to show that the abilities of charismatic practitioners, which many perceived to be magical, in fact had structure and could be learnt by others.

In effect, Bandler and Grinder were interested in theory-in-use, not espoused theory. The claims noted above might be regarded as disingenuous and provocative, challenging the notion that cognitive understanding is essential to effective practice. It is interesting that Bostic St. Clair and Grinder (2001) have recently acknowledged the theoretical 
antecedents to NLP in more detail.

\section{Eclecticism and lack of theoretical coherence}

Although its founders originally identified NLP broadly with psychology (Bandler and Grinder 1975a:1), NLP's contents and practices show influences from diverse fields such as behavioural psychology, cybernetics (Ashby 1965), cognitive psychology (Miller et al 1960), the Palo Alto school of brief therapy (Watzlawick et al 1967), and Chomsky's transformational linguistics.

Craft (2001:125) suggests that NLP is a set of strategies rather than a theory, though argues that principally NLP 'draws on the fundamental assumptions of the theoretical framework of social constructivism' (2001:131). In fact NLP appears to draw on all three groups of learning theory identified by Craft - learning as 'growth' (e.g. its belief in human potential, influenced by Perls and Satir), and learning as 'association' (e.g. the techniques of 'anchoring'), as well as constructivism.

The idea that all knowledge systems must have a unifying theoretical framework is not borne out by the history of ideas. Even so, it seems reasonable to regard NLP primarily not as a theory, but as a praxis that innovates by questioning disciplinary orthodoxy and working across theoretical boundaries. In that sense it is transdisciplinary, yet a theoretical coherence can be inferred at the epistemological level, as suggested above. The unifying features of NLP that merit theoretical explication probably lie in the principles of modelling, not in the diverse techniques. 


\section{Weak linkage to contemporary academic work in relevant fields}

While Dilts and DeLozier (2000) identify many intellectual sources, there is scope for more explicit linkage to contemporary developments in relevant academic disciplines. For example, Robbie (2000) argues that the NLP meta-model needs to be updated in the light of developments in Chomsky's thinking. Cognitive linguistics is a field that appears highly relevant because of NLP's emphasis on the relationship between language and thought. Andreas (2006) makes explicit reference to the work of Lakoff (1987), and it appears that the work of authors such as Chafe (1994), Lakoff and Johnson (1999), and Fauconnier and Turner (2002) may helpfully inform NLP.

\section{The belief that there is research evidence refuting NLP}

Academic research into NLP is thin, with virtually no published investigation into how it is used in practice. Empirical research consists largely of laboratory-based studies from the 1980's and early 1990's (e.g. Baddeley and Predebon 1991; Dorn et al 1983; Poffel and Cross 1985). These investigated two particular features of NLP, the 'eye movement' model (Bandler and Grinder 1979), and the notion of the `primary representational system', according to which individuals have a preferred sensory mode of internal imagery indicated by their linguistic predicates (Grinder and Bandler 1976). Both models hypothesise correspondences between external behaviour and internal processing.

Heap (1988) and Sharpley (1987) argue that these particular claims of NLP cannot be accepted based on the evidence. Heap conducted a meta-analysis of such studies and appears justified in criticising the way claims are made in unequivocal terms in NLP literature. However, Heap appears only to summarise the reported outcomes of those studies, and makes no attempt to appraise their validity. Beck and Beck (1984) have 
argued that some studies reviewed by Heap have problems affecting their reliability. Heap (1988: 276) does acknowledge Einspruch and Forman's (1985) view that 'the effectiveness of NLP therapy undertaken in authentic clinical contexts of trained practitioners has not yet been properly investigated'.

Given these concerns, and the methodological narrowness of the work concerned, we suggest that the existing body of empirical research cannot support definitive conclusions about NLP.

\section{An unclear evidence base for NLP, and a lack of evaluation of its practices}

'Where is the research evidence?' is a familiar cry, although NLP is not alone as a model that is used in education despite lacking empirical support (Coffield et al 2004). The specific nature of the studies that led to the core 'meta-model' (Bandler and Grinder 1975a), including the form the data took and the analysis procedures used, is not set out in detail in published sources. Satir (Bandler and Grinder 1975a: vii) refers to the authors studying hours of video and audio material; McLendon (1989: 5-7) suggests that the data about Perls (who died in 1970) were from transcripts and manuscripts that Bandler edited. The authors did, however, include more data in their studies of Erickson (Bandler and Grinder 1975b, Grinder et al 1977). Bostic St.Clair and Grinder (2001) now provide a retrospective account of how the meta-model emerged through both empirical work and the application of theory from transformational grammar (Grinder's field of expertise).

The need for critical evaluation and research is increasingly acknowledged by NLP practitioners (e.g. Hancox and Bass 1995, Miller 2005) as well as by critics such as 
Eisner (2000), in the field of psychotherapy. NLP's claims clearly warrant formal research, preferably (in our view) through diverse methodological approaches. It appears particularly important to represent the experiences of users and clients ${ }^{\mathrm{xii}}$.

\section{Ethical concerns about the way NLP is used in practice}

There is little doubt that NLP has a reputation to live down. We frequently hear the claim that NLP can be manipulative, a charge noted in the early days of NLP (Bandler and Grinder 1979:7). Using NLP instrumentally for the practitioner's gain is at odds not only with NLP's epistemology but also with its codes of ethics ${ }^{\text {xiii }}$, so concern is entirely appropriate. Yet we have also witnessed outstanding exemplars of ethical practice amongst NLP practitioners, and the suggestion (e.g. Megginson and Clutterbuck 2005) that NLP as a body of ideas is inherently more amenable to unethical use than other modes of working seems far too simplistic. The prime issue seems to be of how ethics are addressed within a field in which it is possible for a layperson to acquire techniques and to practise after relatively brief training (e.g. in the region of twelve days to become a certificated practitioner). This is not to suggest that the solution necessarily lies in professionalisation, which is itself contentious and is in tension with NLP's emphasis on self-determination.

\section{A lack of reflexive critique of NLP's discourse and social practices}

Finally, there is a need for analysis of NLP as a social and historical phenomenon.

Earlier we commented that NLP displays a discourse of self-improvement, with a strong emphasis on the individual, in which the notion of 'excellence' is prominent. Critical projects might include analysis of the social dimension of training courses, which (in 
our experience) is largely ignored. For example, trainers often espouse an evidencebased, sceptical approach, exhorting participants to test NLP's claims for themselves; but we have seen little evidence of awareness of likely constraints on such testing, such as the role of peer pressure, the propensity to believe in something for which one has paid substantial amounts of money, and the risks (whether perceived or actual) for participants of expressing dissent.

The NLP community seems characterised by an extraordinary, creative, if somewhat competitive, emphasis on innovation. Its discourse reflects issues of power and control we have been aware of debates about, for example, who possesses the authority to define NLP; who has greater access to the inside story of NLP's history and development; which camp in the field practices 'true' NLP; and who has legal or moral ownership of NLP and its contents. We assume that such issues arise in any field of practice (psychoanalysis springs to mind as a possible comparison). The challenge for the NLP community, perhaps, is to develop greater reflexive awareness of this dimension of its discourse - which, in a field so deeply interested in the subtleties of language and metacommunication (Bateson 1973), should be possible.

\section{CONCLUSION}

This article has offered an informed introduction to, and appraisal of, NLP. It has argued that NLP is a praxis that appears to be used widely by individual educators, and that NLP can be understood theoretically through Bateson's systemic epistemology. Its identity and distinctive contribution is principally as a methodology, even though the 
field is typically perceived to be a set of techniques. There appears to be much within NLP from which education, training and teaching can benefit; we have also identified seven critical challenges to be addressed. NLP surely merits further research attention, and we advocate academic interest led by a genuine scepticism complemented by greater dialogue between practitioner and academic communities.

\section{Acknowledgements}

We gratefully acknowledge the support of the University of Surrey Scholarship Fund, which has made this project possible, and colleagues in the Centre for Management Learning and Development who critiqued earlier versions of this manuscript. 


\section{REFERENCES}

Andreas, S. (2006) Six blind elephants: understanding ourselves and each other, vol. 1, (Boulder, Colorado, Real People Press)

Ashby, W. (1965) An introduction to cybernetics, (London, Methuen)

Baddeley, M. and Predebon, J. (1991) "Do the eyes have it?": a test of neurolinguistic programming's eye-movement hypothesis, Australian Journal of Clinical Hypnotherapy and Hypnosis 12(1), 1-23

Bandler, R. and Andreas, S. (1985) Using your brain for a change, (Moab, Utah, Real People Press)

Bandler, R. and Grinder, J. (1975a) The structure of magic I: a book about language and therapy, (Palo Alto, California, Science and Behaviour Books)

Bandler, R. and Grinder, J. (1975b) Patterns of the hypnotic techniques of Milton H. Erickson, M.D. vol 1., (Cupertino, California, Meta Publications)

Bandler, R. and Grinder, J. (1979) Frogs into princes, (Moab, Utah, Real People Press)

Bandler, R. and MacDonald, W. (1988) An insider's guide to sub-modalities. 
(Cupertino, California, Meta Publications)

Bateson, G. (1973) Steps to an ecology of mind, (London, Paladin/Granada)

Beaver, D. (2002) NLP for lazy learning: how to learn faster and more effectively, (London, Vega Books)

Beck, C. E. and Beck, E. A. (1984) Test of the eye movement hypothesis of neurolinguistic programming: a rebuttal of conclusions, Perceptual and Motor Skills $58(1), 175-176$

Bostic St.Clair, C. and Grinder, J. (2001) Whispering in the wind (Scotts Valley, CA, J \& C Enterprises)

Brown N. (2003) A comparison of the dominant meta programme patterns in accounting undergraduate students and accounting lecturers at a UK business school, Accounting Education, June, 12(2), 159 - 175

Chafe, W. (1994) Discourse, consciousness and time: the flow and displacement of conscious experience in speaking and writing, (Chicago, University of Chicago Press)

Coffield, F., Moseley, D., Hall, E. \& Ecclestone, K. (2004) Should we be using learning styles? What the research has to say to practice, (London, Learning and Skills Research Centre) 
Craft, A. (2001) Neuro-linguistic programming and learning theory, The Curriculum Journal $12(1), 125-36$

Davis, B. and Sumara, D. (2006) Complexity and education, (Mahwah, NJ, Laurence Eribaum)

Dilts, R (1994) Strategies of genius, (Cupertino, California, Meta Publications)

Dilts, R. (1998a) Modelling with NLP, (Cupertino, California, Meta Publications)

Dilts, R. (1998b) 'Presuppositions' (http://www.nlpu.com/archive.htm, accessed 9.3.2007)

Dilts, R. and DeLozier, J. (2000) Encyclopedia of systemic Neuro-Linguistic Programming and NLP new coding, (Scotts Valley, CA, NLP University Press)

Dilts, R., Grinder, J., Bandler, R. \& DeLozier, J. (1980) Neuro-linguistic programming: volume 1, the study of the structure of subjective experience, (California, Meta Publications)

Dorn, F.J., Brunson, B.I. and Atwater, M. (1983) Assessment of primary representational systems with neuro-linguistic programming: examination of preliminary literature, American Mental Health Counsellors Journal 5(4),161-8

Einspruch, Eric L. and Forman, Bruce D. (1985) Observations concerning research literature on neuro-linguistic programming, Journal of Counseling Psychology 32 (4), 589-596 
Eisner, D. A. (2000) The death of psychotherapy: from Freud to alien abduction, (Westport, CT, Praeger)

Esser, M. (2004) La Programmation neuro-linguistique en débat: repères cliniques, scientifiques et philosophiques (L'Harmattan, Paris)

Fauconnier, G. and Turner, M. (2002) The way we think: conceptual blending and the mind's hidden complexities, (New York, Basic Books)

Freeth, P. (2003) NLP-skills for learning: a practical handbook for increasing learning potential, (Oxford, Communications in Action)

Gordon, D. and Dawes, G. (2005) Expanding your world: modelling the structure of experience, (Desert Rain, www.expandyourworld.net)

Grinder, J. and Bandler, R. (1976) The structure of magic II: a book about communication and change, (Palo Alto, California, Science and Behavior Books)

Grinder, J., DeLozier, J., \& Bandler, R. (1977) Patterns of the hypnotic techniques of Milton H. Erickson, M.D. vol II., (Capitola, CA., Meta Publications)

Hancox, J. and Bass, A. (1995) NLP and academic analysis, Rapport 29, 38 - 40

Harries-Jones, p. (1995), A recursive vision: ecological understanding and Gregory Bateson, (Toronto, University of Toronto Press) 
Heap, M. (1988) Neurolinguistic programming - an interim verdict, in Heap, M. (ed)

Hypnosis: current clinical, experimental and forensic practices, (London, Croom Helm) 268280

Jackson, N. (2004) Developing the concept of metalearning, Innovations in Education and Teaching International, 41 (4), 391 - 403

Knight, S. (2002) NLP at work: the difference that makes a difference in business, (London, Nicholas Brealey Publishing)

Lakoff, G. (1987) Women, fire and dangerous things: what categories reveal about the mind, (Chicago, Chicago University Press)

Lakoff, G. and Johnson, M. (1999) Philosophy in the flesh: the embodied mind and its challenge to Western thought, New York: Basic Books

Linley, P.A., Joseph, S., Harrington, S. and Wood, A.M. (2006) Positive psychology: past, present, and (possible) future, Journal of Positive Psychology, 1(1), 3-16

Lipset, D. (1980) Gregory Bateson: the legacy of a scientist, (London, Prentice-Hall)

McDermott, I. and Jago, W. (2001) Brief NLP therapy, (London, Sage)

McLendon, T. L. (1989) The wild days: NLP 1972 - 1981, (Cupertino, California, 
Meta Publications)

Mathison, J. (2004) The inner life of words: an investigation into language in learning and teaching, $\mathrm{PhD}$ thesis, Department of Educational Studies, University of Surrey

Megginson, D. and Clutterbuck, D. (2005) Techniques for coaching and mentoring, (Oxford, Elsevier Butterwoth-Heinemann)

Miller, C. (2005) Valid and reliable: reflections on NLP and research, Resource, Winter 2005, $19-23$

Miller, G.A., Galanter, E. and Pribram, K. (1960) Plans and the structure of behaviour, (New York, Holt, Rhinehart and Winston)

O’Connor, J. and Seymour, J. (2000) Training with NLP, (London, HarperCollins)

Poffel, S. A. and Cross, H. J. (1985) Neurolinguistic programming: a test of the eye-movement hypothesis, Perceptual and Motor Skills 61(3), 1262

Prosser, M. and Trigwell, K. (1999) Understanding learning and teaching: the experience in higher education, (Buckingham, Open University Press)

Robbie, E. (2000) The ordering principle of the meta model of NLP, NLP World 7(3), 25 - 66

Sharpley, C. F. (1987) Research findings on neurolinguistic programming: 
nonsupportive data or an untestable theory?, Journal of Counseling Psychology, 34(1), $103-107$

Stanton, H. E. (1994) Suggestology and NLP: are there similarities?, Journal of Accelerative Learning and Teaching 19(3), 241-56

Thompson J.E., Courtney, L. and Dickson, D. (2002) The effect of neurolinguistic programming on organizational and individual performance: a case study, Journal of European Industrial Training 26(6), 292-8

Tosey, P., Mathison, J. and Michelli, D. (2005) Mapping transformative learning: the potential of neuro-linguistic programming, Journal of Transformative Education, 3(2). 140 - 167

Tosey, P. and Mathison, J. (2003) Neuro-linguistic programming and learning theory: a response, The Curriculum Journal, 14(3), 361 - 378

Vaihinger, H. (1924) (transl. C. K. Ogden) The philosophy of "as if", (London, Routledge)

Watzlawick, P., Beavin, J.H. and Jackson, D.D. (1967) Pragmatics of Human Communication, (New York, Norton)

\footnotetext{
${ }^{\text {i }}$ We adopt the UK spelling, 'modelling', unless quoting from sources that use the US spelling, ‘modeling'.
} 
ii $\underline{\text { www.NLPresearch.org (accessed 9.3.2007) }}$

iii Information from UK NLP training providers John Seymour Associates (http://www.john-seymour-associates.co.uk/nlpcourseswelcome.php, accessed 9.3.2007), PPD Learning (http://www.ppdlearning.co.uk/, accessed 9.3.2007).

${ }^{\text {iv }}$ UK Council for Psychotherapy

(http://www.psychotherapy.org.uk/experiential_constuctivist.html, accessed 9.3.2007)

${ }^{\mathrm{v}}$ MSc in Organisation Development and Neuro-linguistic Technologies

${ }^{\mathrm{vi}} \mathrm{MSc}$ in Change Agent Skills and Strategies

${ }^{\text {vii }}$ Personal communication, Richard Churches (Lead Consultant, Leadership Development, CfBT Education Trust).

viii The University of Bielefeld, http://www.nlp.de/cgi-bin/research/nlp-rdb.cgi accessed 9.3.2007

${ }^{\text {ix }}$ Personal communication, Dr. Michael Ben-Avie, associate of the Yale University Child Study Center.

${ }^{\mathrm{x}}$ http://theletterworthpress.com/nlpworld/ accessed 9.3.2007 
${ }^{x i}$ http://www.john-seymour-associates.co.uk/whatisnlp.htm accessed 9.3.2007

xii The Institute for the Advanced Studies of Health `NLP Research and Recognition Project' was established in 2006 to assemble evidence of NLP's efficacy (http://www.nlpiash.org/, accessed 9.3.2007)

${ }^{\text {xiii }}$ For example the ANLP general code of ethics (http://www.anlp.org/, accessed 9.3.2007); the NLPtCA code of ethics for psychotherapists

(http://www.nlptca.com/ethics.php, accessed 9.3.2007). 